\title{
Canon van medisch onderwijs
}

Dit jubileumnummer van het Tijdschrift voor Medisch Onderwijs (TMO) markeert het 25-jarig bestaan van het tijdschrift. De redactie heeft daarom een aantal auteurs uitgenodigd aan de hand van een artikel dat is geselecteerd uit de 25-jarige historie van TMO (en daarvoor het Bulletin Medisch Onderwijs) terug te blikken op een bepaald onderwerp, maar vooral naar het heden en de toekomst te kijken. Voor zover de auteurs van 'toen' nog steeds prominent in het betreffende gebied werkzaam zijn, hebben we dezelfde auteurs gevraagd. Wij hopen dat het lustrumnummer van TMO hiermee een bundeling is geworden van actuele visies op onderwerpen die relevant zijn voor de ontwikkeling van medisch onderwijs gedurende de afgelopen vijfentwintig jaar.

Maar laten we wat betreft de geschiedenis nog een stap verder gaan. Wat zijn de gebeurtenissen of wie zijn de personen die de geschiedenis van het medisch onderwijs hebben bepaald? Hoe ziet de canon van medisch onderwijs er uit? Net als de canon van Nederland zoals die 16 oktober jl. door de Utrechtse universiteitshoogleraar Frits van Oostrom, voorzitter van de Commissie Ontwikkeling Nederlandse Canon, werd gepresenteerd, is onze canon geen dictaat van onderwerpen, maar 'opent ze vensters op het verleden'. ${ }^{1}$ Wij komen op de volgende vensters:

\section{Asklepios}

In de klassieke oudheid speelde geneeskunde zich af in de tempel. Eerst in het oude Egypte, ca. 3000 voor Christus, en later tijdens de Griekse beschaving in de persoon van Asklepios, de zoon van Apollo en Coronis. Leunend op zijn staf, met de slang erom heen gekronkeld, openbaarde Asklepios zich aan iedere sterveling die zich in nood tot hem wendde. De zieken, die zich in zijn heiligdom vol vertrouwen te ruste legden, werden tijdens hun dromen door hem genezen. ${ }^{2}$ De geneeskunde was in die tijd, rond 400 voor Christus toen het eerste heiligdom van Asklepios in Athene werd gevestigd, het domein van de goden. Door ervaring kenden de priesters van de Asklepiostempels weliswaar niet de oorzaak, maar meenden zij wel het verloop te kennen van ziektes. Deze kennis werd door de priesters van generatie op generatie overgedragen. Zodoende werd de Asklepiostempel niet alleen een ziekenhuis maar ook een artsenschool. De esculaap zoals we die nog steeds als symbool van het artsenberoep kennen, herinnert ons nog dagelijks aan Asklepios.

\section{Hippocrates}

Hippocrates (ca. 450-370 voor Christus) was één van de belangrijkste vertegenwoordigers van de Asklepioscultus. Hij was afkomstig van Kos en wordt beschouwd als de grondlegger van de wetenschappelijke geneeskunde. Hij zag als eerste in zijn tijd in dat ziekten een natuurlijke in plaats van bovennatuurlijke oorzaak hebben. Voor ons is Hippocrates' naam verbonden aan de artseneed. Hoewel de eed door de eeuwen heen tal van veranderingen heeft ondergaan, wordt de oorspronkelijke tekst door velen nog steeds als gezaghebbend beschouwd. De 
meest recente wijziging van de Nederlandse artseneed vond in 2003 plaats onder leiding van de Commissie Herziening Artseneed. ${ }^{3}$

\section{Eerste universitaire geneeskundeop- leidingen}

De universiteiten van Salerno, Bologna, Montpellier, Parijs en Oxford behoren tot de oudste in Europa en ontstonden na het eerste millennium. Kenmerkend voor de geneeskundeopleiding in de middeleeuwen was de sterke verbintenis tussen medische en algemene kennis. In bijna alle medische faculteiten werd van geneeskundestudenten verlangd dat zij, voordat zij met de studie begonnen, over een universitaire graad 'algemene ontwikkeling' beschikten met vaardigheden op het gebied van debatteren en wiskunde. Vaardigheden in het debat werden verworven in de vakken grammatica, retorica en logica (trivium), vaardigheden op het gebied van de exacte vakken via geometrie, aritmetica, muziek en astronomie (quadrivum). Samen vormden deze vakken de zeven 'artes liberales', de vrije kunsten, waarvan men meende dat ze nodig waren voor de ontwikkelde mens om vrij te kunnen denken. Vaardigheden op deze terreinen vormden de intellectuele bagage die nodig was om medische vragen te kunnen analyseren en begrijpen. ${ }^{4}$

\section{Anatomische les van dr. Nicolaes Tulp}

Dit beroemde schilderij van Rembrandt staat symbool voor een belangrijk aspect van het geneeskundeonderwijs, namelijk de anatomische demonstratie. Het schilderij, dat Rembrandt in 1632 schilderde, is een groepsportret van zeven chirurgijns en de medicus Nicolaes Tulp. Deze gaf tweemaal per week theorieles aan de Amsterdamse chirurgijns. Onderdeel van deze bijscholing was het bijwonen van praktijklessen in het anatomisch theater om meer inzicht te krijgen in de anatomie. Eén keer per jaar was er een openbare sectie, zoals Rembrandt op dit schilderij vastlegde. Het schilderij bevindt zich in het Mauritshuis te 's-Gravenhage. ${ }^{5}$

\section{Abraham Flexner}

Het rapport dat Flexner in 1910 in opdracht van de Carnegie Foundation for the Advancement of Teaching schreef, wordt beschouwd als een mijlpaal in het medisch onderwijs. Het rapport geeft aanbevelingen over de inrichting van het onderwijs: na een periode van scholing in de basisvakken volgt een periode van klinisch onderwijs in de vorm van coassistentschappen. ${ }^{6}$ Dit onderscheid tussen een preklinische en klinische fase van de opleiding is gedurende vele decennia wereldwijd de leidraad voor de inrichting van de geneeskundecurricula geweest. ${ }^{7}$

\section{Probleemgestuurd onderwijs}

Nadat in de zestiger jaren het onderwijsconcept van probleemgestuurd onderwijs (PGO) aan de McMaster University in Canada was ontwikkeld, ${ }^{8}$ heeft de achtste medische faculteit (van de Universiteit Maastricht) dit onderwijsconcept in 1976 in Nederland geïntroduceerd. ${ }^{9}$ Hiermee heeft de Universiteit Maastricht zich op zowel nationaal als internationaal vlak sterk geprofileerd. Inmiddels hebben veel medische faculteiten het concept overgenomen, zij het dat een lokale invulling ervan de verschillende faculteiten van elkaar onderscheidt.

\section{Stationsexamen}

Het stationsexamen is een van de vernieuwingen uit de jaren zeventig. Tot die tijd werden studenten hoofdzakelijk getoetst op theoretische kennis. Bij het stationsexamen wordt informatie verzameld over de medische competentie van studen- 
ten. ${ }^{10} \mathrm{Bij}$ deze toetsmethode wordt gebruik gemaakt van stations: een ruimte waarin een student onder gestandaardiseerde condities een opdracht uitvoert en direct wordt geobserveerd. Vrijwel alle faculteiten hebben stationsexamens in hun toetsprogramma's opgenomen. Het stationsexamen heeft een belangrijke rol gespeeld bij latere toetsontwikkelingen. De laatste jaren zien we een verschuiving optreden naar in-training assessment.

\section{Raamplan}

In Nederland vormt het Raamplan artsopleiding de leidraad voor de invulling van de opleiding. Het eerste raamplan verscheen in 1994 en was daarmee in Europa toonaangevend; de tweede versie verscheen in 2001.11-12 Op dit moment worden de voorbereidingen getroffen voor een derde versie. Het raamplan wordt door de medische faculteiten en studenten gebruikt als richtlijn voor hun onderwijs- respectievelijk studieprogramma. De Wet BIG refereert voor het omschrijven van de bekwaamheden van artsen aan het Raamplan artsopleiding 1994.

\section{CanMEDS-competentiemodel}

Dit model beschrijft de verschillende terreinen waarop een medisch specialist expert behoort te zijn. Het CanMEDS-model is ontwikkeld in Canada, maar wordt inmiddels in vele landen, waaronder ook Nederland, gebruikt als leidraad bij de modernisering van de medisch specialistische vervolgopleidingen. ${ }^{13}$ Volgens dat model vervult de arts zeven rollen. In het Engels zijn dat de rollen van medical expert, communicator, collaborator, manager, health advocate, scholar en professional. De medical expert is de deskundige die effectieve en ethisch verantwoorde patiëntenzorg biedt. De communicator is degene die in staat is tot een goede communicatie met de patiënt en zijn of haar omgeving. De collaborator is degene die goed samenwerkt met collegae en andere zorgverleners. De manager is degene die effectief en efficiënt werkt en bijvoorbeeld een goede balans vindt tussen werk en persoonlijke ontwikkeling. De health advocate is degene die goed functioneert binnen de gezondheidszorg in brede, maatschappelijke zin en adequaat omgaat met fouten in de zorg. De vertaling van de scholar is interessant, omdat dat enerzijds de rol is van degene die zelf leert en bijschoolt en anderzijds de rol is van de docent die anderen schoolt. En tenslotte, de professional als degene die professioneel handelt volgens de standaard van de beroepsgroep, maar ook degene die de grenzen van zijn eigen kunnen goed kent en daar naar handelt. De nieuwe Raamplancommissie krijgt nadrukkelijk de opdracht bij de aanpassing van het raamplan voor de basisopleiding in Nederland aansluiting bij het CanMEDS-concept te zoeken.

\section{De redactie}

\section{Literatuur}

1. BEntoen.nu. De canon van Nederland [homepage op internet] [geciteerd 3 november 2006]. Beschikbaar op: http://www.entoen.nu.

2. Schouten J. De slangestaf van Asklepios als symbool van de geneeskunde [dissertatie]. Leiden: Rijksuniversiteit Leiden; 1963.

3. Nederlandse artseneed. Commissie Herziening Artseneed. Utrecht: VSNU; 2003.

4. Burns CR. The humanities and modern medical education. In: Kerkhoff AHM, Luyendijk-Elshout AM, Poulissen MJD, editors. De novis inventis. Essays in the history of medicine. Amsterdam: Holland University Press; 1984.

5. 1606-2006. Rembrandt 400 [homepage op internet] [geciteerd 3 november 2006] Beschikbaar op: http://www.holland.com/rembrandt 400

6. Flexner A. Medical education in the United States of America and Canada. A report to the Carnegie Foundation for the Advancement of Teaching. New York: Heritage Press; 1910.

7. Cooke M, Irby DM, Sullivan W, Ludmerer KM. American medical education 100 years after the Flexner report. N Engl J Med 2006;355:1339-44. 
8. Barrows HS. How to design a problem-based curriculum for pre-clinical years. New York: Springer; 1985.

9. Vleuten CPM van der, Scherpbier AJJA, Wijnen WHFW, Snellen-Balendong HAW. Flexibility in learning: a case report on problem-based learning. International Higher Education 1996;1:17-24.

10. Luijck van SJ, Vleuten van der CPM. Het stationsexamen. In: Metz JCM, Scherpbier AJJA, van der Vleuten CPM, editors. Medisch onderwijs in de praktijk. Assen: Van Gorcum; 1995.

11. Metz JCM, Pels Rijcken-van Erp Taalman Kip $\mathrm{EH}$, van den Brand-Valkenburg BWM, editors.
Raamplan 1994 artsopleiding: eindtermen van de artsopleiding. Nijmegen: Universitair Publicatiebureau; 1994.

12. Metz JCM, Verbeek-Weel AMM, Huisjes HJ, editors. Raamplan 2001 artsopleiding: bijgestelde eindtermen van de artsopleiding. Nijmegen: Mediagroep; 2001.

13. Frank JR, Jabbour M, Tugwell P, et al. Skills for the new millennium. Report of the societal needs working group, CanMEDS 2000 project. Ann R Coll Physicians Surg Can 1996;29:206-16. 